\title{
The beliefs and values of police volunteers
}

Andrew Millie

Pre-publication version

Published as: Millie, A. (2018) 'The beliefs and values of police volunteers', in K.

Bullock and A. Millie (eds.) The Special Constabulary: Historical Context,

International Comparisons and Contemporary Themes, Abingdon: Routledge.

\section{Introduction}

In this chapter, the focus is on the beliefs and values of police volunteers in Britain, concentrating in particular on special constables and police support volunteers (PSVs). The chapter draws on an empirical investigation into volunteering within Lancashire Constabulary (Millie, 2016a).

Everything we do in life is influenced by some form or combination of value judgements. For those who consider joining the police - either as a paid regular or as a volunteer - such judgements will influence decisions on working with or for the police, the kind of regular officer or volunteer they aspire to be, and the kind of regular or volunteer they become. Value judgements may be economic regarding the worth of something or someone. They may be prudential judgements regarding our quality of life and what may have a positive or negative impact on that quality of life. They may be aesthetic judgements related to our senses and tastes, or moral judgements related to what is perceived as right and good, or what ought to be done (Millie, 2008; 2016b). Of relevance to policing, such value judgements have an impact on the type of policing we want, as well as the type of policing we get. For instance, William Bratton (1995) famously focused on quality-of-life policing, on minor infringements that are perceived to have a detrimental impact on others' quality of life - such as "street prostitution, lowlevel drug dealing, underage drinking, blaring car radios and a host of other quality-oflife crimes that contribute to a sense of disorder and danger on the street" (Bratton, 1995: 447-448). Alternatively, policing can focus on economic value judgements, prioritising crimes and anti-social behaviours that have an impact on the economic vitality of a shopping mall, district, city or region. For good or ill, value judgements can work together. For instance, a focus on economic vitality may interact with an aesthetic judgement regarding who or what are deemed to be visibly appropriate for an economically successful district. If working alongside Bratton's quality-of-life value judgements, the result can be disproportionate policing of homeless populations, young people or other minorities whose visible presence is deemed to impact the quality of life of others, and who are then banished to more 'appropriate' areas (Beckett and Herbert, 2010). There are also moral value judgements regarding what is deemed to be 
right, or what ought to be; yet the morally right thing to do can also be over-ridden by other priorities.

Within the academic policing literature there is much that is written on the culture of the police (e.g. Manning, 1989; Chan, 1997; Waddington, 1999; Loftus, 2009; Cockcroft, 2013). For instance, according to Janet Chan (1997: 110) 'police culture' relates to the police's 'informal occupational norms and values' that operate under the 'apparently rigid hierarchical structure of police organisations'. Peter Manning (1989: 36) alternatively talks of 'accepted practices, rules and principles of conduct . . . generalized rationales and beliefs'. There seems to be a dominant occupational culture that is often resistant to change, despite the best efforts of police reformers (Loftus, 2009). This 'cop culture' (Reiner, 1978) has developed its own set of dominant beliefs and values. Of course, to talk of a single police culture is a mistake (Cockcroft, 2013), with different departments or groupings within the police displaying plural sub-cultural beliefs, values and practices.

This chapter considers the beliefs and values of police volunteers, who represent an often overlooked aspect of policing. The chapter considers the development of a volunteering sub-culture that overlaps with, but to a certain extent runs parallel to, dominant cultures displayed by regular paid officers. Two aspects of British police volunteering are considered, these being the special constabulary and the more recently established PSVs. Special constables work alongside regular police officers and so their beliefs and values will be influenced by those of regulars. Special constables are compared to PSVs who sometimes work with regular officers, but - depending on role - may also have little or no contact with regulars.

The chapter draws on a qualitative study of police volunteering within Lancashire Constabulary $^{1}$ (Millie, 2016a). The research was funded by Lancashire Constabulary, but was an independent project. The study took place during 2016 and adopted a Participatory Action Research approach in which police volunteers were actively involved in the co-production of knowledge (Kindon et al., 2007). To this end, four PSVs worked alongside the author in interviewing members of the special constabulary and other PSVs. The volunteer interviewers were recruited through an internal police advert. They were initially interviewed by the author as part of the study and then given training in interview techniques, ethics ${ }^{2}$ and analysis to become interviewers themselves. Once all the interviews were completed a further meeting took place between the author and three of the volunteer interviewers to discuss initial findings. In total, 9 special constables and 16 PSVs were interviewed, with six interviews conducted by the project lead and the remaining 19 by the volunteer interviewers. The interviews took a maximum of an hour each, they were recorded, transcribed ${ }^{3}$ and analysed for key and emerging themes. In what follows, the 'place' of police volunteers is considered within the context of police codes of ethics. Following this, the beliefs and values of volunteers are looked at in more depth. But first some background to police volunteering is provided including its role in social control. 


\section{Background}

Criminological literature has identified a plethora of social control agents, from the informal controlling influence of family, friends and neighbours, through to more formal control from the police and state (see e.g. Cohen, 1985). There are malign as well as benign effects of social control, including when exerted by the police, and the social control the police exercises tends to be conservative aimed at reproducing the existing social order (Ericson, 1982) as dictated by the value judgements of those with requisite political capital (Millie, 2013; 2014). The involvement of volunteers within policing may be a challenge to this status quo. The police service has been waking up to what Michael Banton (1964: 1) noted in the 1960s, that the police 'are only one among many agencies of social control'. With increased pluralisation of security provision (Jones and Newburn, 2006), various private and local authority employed security agents have been testing the state police's dominance. It is possible that the involvement of volunteers in state policing - either in the form of special constables or PSVs - can be a valuable aspect of what is now a complicated policing landscape. Volunteers can challenge dominant conservative policing orthodoxies and act as a brake on more malign aspects of control, and maybe also improve legitimacy. Such benefits will of course depend on how the beliefs and values of volunteers align with or challenge dominant cultures and practices.

As is covered elsewhere in this volume, there is a long history of volunteering within the British police, most notably since the introduction of uniformed and warranted but unpaid - special constables from the early nineteenth century onwards. Much more recently there has been a push to broaden the use of volunteers, to nurture what Adam Crawford and Stuart Lister (2004) called civilian policing, or what is more broadly seen as part of an extended policing family (Crawford, 2013). Whilst there is a lack of literature on the special constabulary (e.g. Seth, 1961; Millie and Jacobson, 2002; Bullock, 2015a), there is even less on PSVs (an exception being Bullock, 2015b).

Early non-uniformed police volunteers came in the form of Neighbourhood Watch groups. Inspired by the United States' introduction of Neighbourhood Watch in the late 1960s (Washnis, 1976), the scheme was introduced in the United kingdom from the mid-1980s onwards (Bennett, 1990). It has since expanded to encompass various Home Watch, Farm Watch or Business Watch schemes. Volunteers started to appear in other areas too. For instance, from the early 1990s volunteers could be seen on supplementary visible patrol or staffing police station front counters that had been threatened with closure (Crawford and Lister, 2004; Millie, 2012; Bullock, 2015b). Those engaged in such volunteering activities became badged as PSVs (Bullock, 2014). The use of PSVs was further promoted by the 2010-2015 coalition and post-2015 Conservative government under the 'Big Society' banner with the aim to be 'redistributing power from the state to society; from the centre to local communities, giving people the opportunity to take more control over their lives' (The Conservatives, 2010: 37). PSVs 
can be engaged in a very wide range of activities. For example, those that were interviewed as part of this study were volunteers within police complaints, Cadet leadership, Community Road Watch, early action, restorative justice, work on foreign language phone lines, administration, audit work, role play, crime trend analysis, survey work, work with vulnerable victims, supporting the local Neighbourhood Policing Team, custody visiting, and holding voluntary positions on various advisory groups and panels (Millie, 2016a). According to the College of Policing, there are over half a million volunteers working for the police across England and Wales, including special constables, PSVs, Cadets and various Watch Schemes (College of Policing, undated). At the time of writing, all come under the official heading of 'Citizens in Policing' (see e.g. Callender, 2016).

The 25 respondents were an opportunistic sample and so did not represent the views of all special constables and PSVs in Lancashire Constabulary. That said, the range of policing experience that they had is worth noting, from just a few months for new recruits, through to one respondent who had been in the special constabulary for 36 years. Another had been volunteering for the police as a special constable and then a PSV for 44 years. The amount of policing experience volunteers have cannot be underestimated - and should not be under-utilized. Furthermore, volunteers have also a lot of experience from outside the police that they can bring with them. Many volunteers enjoy applying the skills they already possess to a police setting, as a 70year-old female PSV put it, 'I'm looking for challenges; I'm looking for work that complements my skills' (PSV 3). Yet managers need to be aware that some volunteers are keen to do something completely new, as a 29-year-old male PSV put it, 'It's actually nice to use a completely different skillset' (PSV 4). For one male special constable aged 46, 'I work in IT security in my day job which is very desk focused, and I looked upon the volunteering side of it as a way of getting out from behind my desk and getting out and meeting people' (Special 9). Just as volunteers' experience and skills - and desire to use new skills - vary, so too do the beliefs and values that they bring with them. In the next section, the 'place' of police volunteers within various police codes of ethics is considered. Following this, the beliefs and values of volunteers are looked at in more depth.

\section{Volunteers' beliefs and values}

In 1995 the seven principles of the Nolan Committee on Standards in Public Life were published. In the two decades since the need for improved standards and values for policing were highlighted, there have been developments in Codes of Ethics in Northern Ireland (2003), Scotland (2013) and across England and Wales (2014). The College of Policing's Code of Ethics for England and Wales features nine principles of policing which include the original Nolen Committee list, but with the addition of 'fairness' and 'respect'. The full list of nine principles is accountability, fairness, honesty, integrity, leadership, objectivity, openness, respect and selflessness (see also Chapter 9 by Vince Straine-Francis in this volume). It is hard to argue against such a list. For Peter Neyroud 
(2003) having a code of ethics is essential for the wider promotion of professional values in policing. Yet, as noted, distinct 'cop cultures' have evolved with their own set of dominant beliefs and values which do not necessarily align with those promoted by the code of ethics. Drawing on the work of Robert Reiner (1978; 2010), Louise Westmarland (2016: 364-365) has summarised an alternative 'cop culture code of ethics' as including

1. A sense of mission - to catch bad people and lock them up; be on the side of victims; make society better

2. Cynicism/pessimism - that an officer's hands are tied as criminals do not have a code of ethics; everyone is on the take or bending rules, and difficult issues are dealt with daily

3. Suspicion - that most people are either 'good citizens' or 'police property'; that officers need to be careful who they tell they're a cop; be streetwise as people take advantage

4. Isolation/solidarity - don't tell on your mates, it's us versus them, there's a blue code of silence/trust/inclusion

Of relevance to the special constabulary and other police volunteering, Westmarland (2016: 365) noted, "The "blue code" of inclusivity/silence/trust does not normally extend to police support staff, special constables or former colleagues who are now supervisors'. From this point of view, volunteers are excluded from the dominant police culture. An interviewee in Reiner's, 1978 study summarised cop culture as follows: 'It's a sect - it's like a religion, the police force' (Reiner, 1978: 247). There is a divide between regular cops within the 'sect', and others working within the police organisation.

Yet in the current study, such a divide was less apparent - at least from the point of view of the volunteers. For instance, according to a 46-year-old male special constable, the regular officers in his area have 'always been very pro-specials' (Special 9). He expanded by saying that, 'I know historically specials were seen as overtime thieves but I've certainly not seen anything negative towards specials at all'. A 19-year-old male special constable thought, 'You can feel as though you are being more of a burden. ... that's not always how they act ... The regulars I have worked with have been really nice' (Special 7). The PSV interviewees in the study were similarly complementary of regular officers. According to a 69-year-old female PSV, 'I'm always welcomed. I don't feel intimidated whatsoever' (PSV 12). According to a 76-year-old male PSV, 'Oh, can't fault it, you know they are excellent, you know, whatever rank. I have never had a problem there; they are always very civil, very pleasant'.

It seems there could be broader acceptance of volunteers than previously thought although it is of course possible that different answers may have been forthcoming had we asked regular officers for their views on volunteers (see Gill and Mawby, 1990). Despite the volunteers' enthusiasm towards the regulars, the study did identify divides, 
most notably that special constables and PSVs were regarded as subservient to regular officers. For example, although some special constables regarded their role to be the same as regular paid officers, most saw their job as being supportive of whatever regulars are doing. According to one 19-year-old male special constable, his job was 'to assist the regulars, to serve the people' (Special 7). For another special constable, this time a 46-year-old male, 'we certainly can't replace the regular officers . . . I think we do a very good job of supporting the police officers and the constabulary' (Special 9). According to a 66-year-old female PSV, her job was, 'to help save police time, to enable them to do their role' (PSV 1). For a 33-year-old female PSV, the job of the volunteer is 'to support and work alongside the staff, work alongside staff and help them to do what they are doing, to support and assist them' (PSV 10).

Providing support to the regulars is clearly important, but rather than being subordinate, it is possible that the volunteer is equal to any regular. Volunteering within the police is promoted in order to improve police legitimacy, to improve community representation and to provide a 'bridge' between the regulars and communities (NPIA, 2008; Bullock, 2014; Millie, 2016a). If these aims are important then volunteers need to be regarded as something more than 'an extra pair of hands' (Special 20), more than an extra body on a Friday night patrol, and more than someone who comes in and does the jobs that nobody else wants to do. Yet the police service remains strictly hierarchical and an unpaid special constable is going to be lower down the pecking order. Even lower is the unpaid and unwarranted PSV. Some volunteers enjoy doing menial tasks and are happy having a purely supportive role, but volunteers have something unique to offer the police and this position needs to be respected - as a 70-year-old female PSV identified:

I always maintain, I don't work for the organisation, I work with the organisation, and there's a very big difference. A volunteer works with you, he doesn't work for you, and that's the difference. If I work for you, you're employing me, and I'm stuck with you. As a volunteer, I work with you, and if I don't like what I get, I'll walk away. (PSV 3)

Volunteers' motivations for working 'with' the police vary from the charitable or altruistic through to the instrumental (see also Chapter 5 by Graham Hieke and Chapter 7 by Karen Bullock). For instance, many forces now see special constables as a source of recruits for regular officers, preferring to take people on who have already gained suitable experience and training through the special constabulary. The result has been a growth in the number of young people who are special constables, often volunteering whilst completing university degrees. According to one male 19-year-old special constable:

What motivates me is I want to be a regular, I want to join the police service. Specials was definitely a good way in, good insight, a kind of a taster to see if actually I'd enjoy the police. (Special 20) 
For another special constable, a 20-year-old female who is a student at a local university, 'I hope to join the regulars when I've graduated. But if not I appreciate the fact that [the] specials is basically a, kind of like, "CV booster", (Special 11). A 33 year-old male claimed he joined because 'I just wanted to better myself altogether', but then elaborated by stating, 'I think being a special and then getting into the regulars would be a great way to improve those skills' (Special 7). Some people do still volunteer for the special constabulary simply because they want to be special constables. For Special 9, a 46-year-old male, 'I thought that helping the police out would be probably a pretty unique type of volunteer work'. Similarly, for Special 17, a 33-year-old male, 'it's something I've always wanted to do . . . even though it's voluntary it's sort of, I don't know, it gives me a sense of pride being able to do it'. Some special constables were concerned with the emphasis being placed on the special constabulary as a training ground for regular officers. For instance, according to a 41year-old male special constable:

Instead of being cheap labour until they join as regulars, they could look at what the police call career specials, which are people like me really that have no intention of joining, and using us better. (Special 22)

This officer had been a special constable for six years, enjoyed this role and had no desire to join the regulars. The changing age profile for the special constabulary was recognised by a 46-year-old male special constable who noted, '[we] seem to have a large number of very, very young specials who typically are students' (Special 9). That said, not all were against the special constabulary's changing profile. According to a 59-year-old special constable, 'The special constabulary has to adapt with the times' (Special 6).

As for the PSVs, some volunteered to prevent boredom and 'fill their time' postretirement; yet most PSVs and special constables volunteered because they saw it as useful for the community. For instance, when asked why she volunteered for the police, a 70-year-old female PSV stated,

Because I'd taken early retirement, and I wanted to fill my time. Tried one or two things, didn't like them, didn't enjoy them, looked round for something that would challenge me, that would fill my time, that would give me satisfaction, for which I could contribute, because I want to give back. I really, sincerely think you give back. (PSV 3)

Similarly, a 20-year-old female special constable stated, 'I always feel like I need to give something back. I know everyone says that, but that is just how I feel. People have helped me so I need to help them' (Special 11). For one PSV who volunteered on a Chinese language helpline, it was an opportunity to help the Chinese community. A sense of community - and of giving back - was strong among many of the volunteers. 
Similarly, it was thought that volunteering attracted a certain 'type' of person that believed in community. According to PSV 24, a female volunteer in her 50s, 'In order to do all this volunteering, you've got to be of a certain character'. If true, it will be useful to know more about the beliefs and values of those who volunteer.

When asked about their personal values and beliefs, responses from volunteers were often framed in terms of the 'Golden Rule'. This is an idea common across a number of religions and cultures, but notably expressed in the Biblical instruction to 'do to others what you would have them do to you' (Matthew 7:12). ${ }^{4}$ For instance, according to Special 17, a 33-year-old male, 'I treat people how I'd like to be treated myself'. Similarly, a 69-year-old female PSV claimed, 'I treat people, hopefully, as they would treat me' (PSV12). For PSV2, a 68-year-old male, he tries to 'do unto others as you'd like them to do to you'. There is the possibility that respondents said this because it is the kind of thing that 'sounds right', it is the right kind of response to give when asked about values. Yet, even if it is more aspiration that reality, an emphasis on the Golden Rule can have an impact on policing culture and decision making. In simple terms, if the police want to be treated well, to be respected by others, then those who work for, or volunteer with, the police must respect others and treat them well (Millie, 2016b). This is a challenge to the 'cop culture code of ethics' outlined earlier, yet volunteers can make a contribution to this change of culture. Not only can they act as a bridge to the community, many are also motivated by a desire to help the communities the police serve.

The themes of integrity and honesty were picked up by some interviewees, often relating these to the College of Policing Code of Ethics. According to a 70-year-old female PSV:

The College of Policing have produced a code of ethics ... I totally subscribe to that ... So, I'm talking about integrity and honesty and reliability, etc., etc. And I would say I subscribe to those . . . I also very, very firmly believe that you've got to give something back. (PSV 3)

Similarly, according to a 19-year-old male special constable, he believes he has, 'pretty much the exact values that the police have: honesty, integrity. At the end of the day we're there to do the job' (Special 20). For a 76-year-old male PSV, 'I always feel I am representing the constabulary and that I should be seen as a standard and not to let the constabulary down ... To set the standard and, for want of a better phrase, a role model in a way' (PSV 8).

The volunteers also highlighted the need to help others, of doing the right thing, being decent and kind, offering support and being accepting. Many of these traits can be summarised in terms of 'respect'; as a 66-year-old female PSV put it, the need to 'accept people for what they are' (PSV 1). Similarly, a 29-year-old male PSV stated, 'It's important that everyone's got a voice ... it's also important that everyone's respected 
for who they are, their beliefs' (PSV 4). According to Special 14, a 19-year-old male, 'everyone should be treated the same'. It is hard to argue against such a statement and its meaning needs some unpicking. For instance, it is possible to treat everyone badly and be treating them the same, although I assume this is not what was meant. He did add that it is important not to make 'anyone feel like they are inferior'. A 53-year-old male special constable provided further elaboration:

You should treat everybody with the respect that they deserve, you know, dealing with people that you deal with as a volunteer . . . It's not for me to judge them ... they can be horrible, nasty, rude, obnoxious, wanting to fight you kind of people, but you know I just deal with them in a way that's like, 'Well I'll be kind to you even if you're being aggressive to me. If you want to carry on being aggressive, that's fine, but you're not going to make me into something that I'm not because you want to fight me'. (Special 18)

The philosopher Stephen Darwall (1977) has talked of there being two types of respect, these being appraisal respect and recognition respect. Appraisal respect relates to the kind of respect someone earns for being good at something, such as sport or perhaps doing a job well. It is based on merit and is hierarchical (see also Millie, 2009; 2016b). The entry requirement for gaining respect is whether you have done enough to earn that respect. Alternatively, for recognition respect people are 'entitled to have other persons take seriously and weigh appropriately the fact that they are persons in deliberating about what they do' (Darwall, 1977: 38). In short, drawing on Immanuel Kant's notion of dignity, people should be treated with respect because they all have an inherent dignity as a person. This is the kind of respect that Special 18 refers to - that despite some people being 'horrible, nasty, rude, obnoxious, wanting to fight you kind of people', you should not reply in kind, but instead 'treat everyone with the respect that they deserve'. As noted, if the police want to be treated well, then they must treat others well. Of course, not all volunteers will have the same beliefs and values, and will have different ideas on how they fulfil their policing role, but an emphasis on respect was common among the interviewees. Furthermore, highlighting recognition respect will further challenge dominant 'cop culture' codes of ethics. A broader embrace of recognition respect may also challenge the police hierarchy that leaves special constables and other volunteers as subordinate to regular officers.

As noted, there is an apparent 'cop culture code of ethics' (Westmarland, 2016) centred on a sense of mission, cynicism/pessimism, suspicion and isolation/ solidarity. It is possible that there are overlaps between this dominant 'cop culture' and the sub-cultural norms and practices of volunteers. This may be especially true for the many special constables who join as a route into the regular force. For instance, according to a 41year-old male special constable, 'Especially for some of the younger ones, that all they want to do is sit in cars and blue lights flashing. That's what they join for' (Special 22), or as a 20-year old female special constable put it when asked what it was like when she first put on her uniform: 
It was very exciting. You find that people look at you and you are just like 'what are they looking at?' And then you realise, oh I've got my uniform on, it is really strange. (Special 11)

Recruits who have instrumental motivation for joining the special constabulary are perhaps more likely to integrate into the dominant cop culture. The way forces currently utilise the special constabulary furthers this assimilation. According to a special constable in his 50s:

Nowadays, the specials are, we say they're fully integrated. The majority of specials, when they join, work with response teams, and they sit next to a response officer, and they're going to jobs with blue lights and things, and in essence, we throw them in at the deep end, and that's the experience they like and want, and that's the very latest model. (Special 6)

There are clear benefits of such an approach which more fully utilises the resources available, yet there is also greater exposure to the good and the bad of 'cop culture'. Historically, the special constabulary has had its own culture distinct from the regulars; however, with increased use of the special constabulary as a recruitment tool for regular officers this distinction is under threat. The broader volunteering culture within the police is a challenge to the dominant cop culture, with many volunteering for charitable or altruistic reasons rather than having instrumental motivation. Of course, many paid officers also join because of what they can do for their community. Yet there is also much that regular officers can learn from their volunteering colleagues.

\section{Discussion and conclusions}

Very little is known about those who volunteer for the police. In this chapter, the beliefs and values of special constables and PSVs have been considered. When talking about their values and beliefs, many volunteers referred to the need for respect. This was sometimes expressed in terms of recognition respect that sees all as due our respect, irrespective of whether we approve of what they do (Bagnoli, 2007). A broader embrace of this more egalitarian respect would be a challenge to police practice. It would also be a challenge to the dominant culture and hierarchy that sees volunteers as subordinate to regular officers.

Some volunteers embrace this subordinate relationship, that they are there to enable regular officer simply 'to do their role' (PSV 1). In this chapter, I have questioned this logic. If community links and improved legitimacy are important, then volunteers need to be seen as something higher. Given the experience and skills they bring with them, volunteers ought to be seen as equals to paid officers. That said, the volunteers themselves do perceive there to be generally good relations with regular officers. 
While many volunteers are enthusiastic about using their skills within a policing setting, an important finding is that some would rather learn new skills and do something that is different to what they have done before. Volunteering for the police becomes an opportunity to explore new things.

The chapter opened with consideration of different types of value judgement, based on economic, prudential, aesthetic and moral judgements. Those who volunteer can be guided by a combination of economic judgement (that I can afford to give my time freely, or that volunteering will hopefully lead to paid employment), prudential judgement (that being a police volunteer will positively impact my quality of life, and perhaps the quality of life of others), and moral judgement (that volunteering allows me to give something back to the community). Aesthetic judgements are not a dominant consideration - although Special 11 was quite excited when she first put on her uniform. Similarly, for Special 7, a 19-year-old male, 'I've really enjoy wearing a uniform, it is something to be proud in'. The semiotic meaning behind the uniform is perhaps an attraction for some.

Consideration of the values and beliefs that police volunteers bring with them is an important step to understanding the type of people who volunteer and what they can contribute. Whilst there are clear overlaps with the dominant police culture, volunteers offer something different and take policing in a different direction. Rather than volunteers being subsumed by the dominant cop culture, with greater use of volunteers, perhaps regular officers will gain greater exposure to the sub-cultural beliefs and values of volunteers. If these beliefs and values are characterised by a desire to give back to the community, by the Golden Rule and by an egalitarian recognition respect that sees inherent dignity in all, then this can only be positive.

\section{Notes}

1 The research was funded by Lancashire Constabulary and utilised police support volunteers as volunteer interviewers. However, what are presented here the views of the author, and not necessarily those of the Force.

2 The project adhered to the British Society of Criminology code of ethics and received ethical approval from Edge Hill University.

3 Twenty-four out of 25 interviews were recorded and transcribed. Detailed noted were taken of the twenty-fifth interview.

4 New International Version

\section{References}

Bagnoli, C. (2007) 'Respect and membership in the moral community', Ethical Theory and Moral Practice, 10(2), 113-128.

Banton, M. (1964) The Policeman and the Community. London: Tavistock Publications. 
Beckett, K. and Herbert, S. (2010) Banished: The New Social Control in Urban America. New York, NY: Oxford University Press.

Bennett, T. (1990) Evaluating Neighbourhood Watch. Aldershot: Gower.

Bratton, W.J. (1995) 'The New York City Police Department's civil enforcement of quality-of-life crimes', Journal of Law and Policy (Brooklyn Law School), 3(2), 447464.

Bullock, K. (2014) Citizens, Community and Crime Control. Basingstoke: Palgrave Macmillan.

Bullock, K. (2015a) 'Diversity in the special constabulary', Policing, A Journal of Policy and Practice, 9(1), 46-55.

Bullock, K. (2015b) 'Shoring up the 'home guard'? Reflections on the development and deployment of police support volunteer programmes in England and Wales', Policing and Society, 27(4), 342-357.

Callender, M. (2016) 'Reimagining the volunteer: A new chapter for police volunteering', Policing Insight, Available at:

https://policinginsight.com/analysis/new-chapter-policevolunteering/ [Accessed 5 October 2016].

Chan, J. (1997) Changing Police Culture: Policing in a Multicultural Society. Cambridge: Cambridge University Press.

Cockcroft, T. (2013) Police Culture: Themes and Concepts. Abingdon: Routledge.

Cohen, S. (1985) Visions of Social Control. Cambridge: Polity Press.

College of Policing (undated) Citizens in Policing, Webpage, Available at: www.college.police.uk/What-we-do/Support/Citizens/Pages/default.aspx [Accessed 15 August 2016].

The Conservatives (2010) Invitation to Join the Government of Britain, Conservative Party Election Manifesto. London: The Conservatives.

Crawford, A. (2013) 'The police, policing and the future of the extended policing family', in J.M. Brown (ed.) The Future of Policing. Abingdon: Routledge. 173-190.

Crawford, A. and Lister, S. (2004) The Extended Policing Family: Visible Patrols in Residential Areas. York: Joseph Rowntree Foundation. 
Darwall, S.L. (1977) 'Two kinds of respect', Ethics, 88(1), 36-49.

Ericson, R.V. (1982) Reproducing Order: A Study of Police Patrol Work. Toronto: University of Toronto Press.

Gill, M. and Mawby, R. (1990) A Special Constable: A Study of the Police Reserve. Aldershot: Avebury.

Jones, T. and Newburn, T. (eds.) (2006) Plural Policing: A Comparative Perspective. Abingdon: Routledge.

Kindon, S., Pain, R. and Kesby, M. (2007) 'Introduction: Connecting people, participation and place', in S. Kindon, R. Pain and M. Kesby (eds.) Participatory Action Research Approaches and Methods: Connecting People, Participation and Place. Abingdon: Routledge.1-7

Loftus, B. (2009) Police Culture in a Changing World. Oxford: Oxford University Press.

Manning, P.K. (1989) 'Occupational culture', in W.G. Bailey (ed.) The Encyclopedia of Police Science. New York, NY: Garland.472-475.

Millie, A. (2008) 'Anti-social behaviour, behavioural expectations and an urban aesthetic', British Journal of Criminology, 48(3), 379-394.

Millie, A. (ed.) (2009) Securing Respect: Behavioural Expectations and Anti-Social Behaviour in the UK. Bristol: Policy Press.

Millie, A. (2012) 'Police stations, architecture and public reassurance', British Journal of Criminology, 52(6), 1092-1112.

Millie, A. (2013) 'The policing task and the expansion (and contraction) of British policing', Criminology and Criminal Justice, 13(2), 143-160.

Millie, A. (2014) 'What are the police for? Re-thinking policing post-austerity', in J. Brown (ed.) The Future of Policing. London: Routledge.52-63.

Millie, A. (2016a) Volunteering Within the Police: Experiences of Special Constables and Police Support Volunteers, A Report for Lancashire Constabulary. Ormskirk: Edge Hill University.

Millie, A. (2016b) Philosophical Criminology. Bristol: Policy Press. 
Millie, A. and Jacobson, J. (2002) Employee Volunteering and the Special

Constabulary: A Review of Employer Policies. London: The Police Foundation.

Neyroud, P. (2003) 'Police and ethics', in T. Newburn (ed.) Handbook of Policing. Cullompton: Willan.578-602.

NPIA (2008) Special Constabulary National Strategy Implementation Advice.

London: NPIA, Available at: http://library.college.police.uk/docs/npia/Specials-ImpStrategyupdated.pdf [Accessed 5 October 2016].

Reiner, R. (1978) The Blue-Coated Worker: A Sociological Study of Police Unionism. Cambridge: Cambridge University Press.

Reiner, R. (2010) The Politics of the Police, Fourth Edition. Oxford: Oxford University Press.

Seth, R. (1961) The Specials: The Story of the Special Constabulary in England, Wales and Scotland. London: Victor Gollancz.

Waddington, P.A.J. (1999) 'Police (canteen) sub-culture - an appreciation', British Journal of Criminology, 39(2), 287-309.

Washnis, G.L. (1976) Citizen Involvement in Crime Prevention. London: Lexington Books.

Westmarland, L. (2016) 'Governance of policing and cultural codes: Interpreting and responding to policy directives', Global Crime, 17(3-4), 352-369. 